\title{
El amor social, condición necesaria para alcanzar el bien común
}

\section{Cristina de la Cruz Ayuso'}

Palabras clave: bien común, caridad socio-política, justicia social.

Key words: common good, socio-political charity, social justice.

Mots clés: bien commun, charité socio-politique, justice sociale.

El concepto de "amor social" aparece nombrado en la encíclica de manera explícita en algunos apartados aunque en toda ella subyace de manera latente un eco a una dilatada tradición filosófica, teológica y de pensamiento que nos recuerda el carácter y alcance político del amor (y de la caridad). Su praxis en la vida pública, cívica y política está relacionada con un profundo compromiso por la justicia con los pobres y el bien común. Es definido como la afirmación y reconocimiento comunitario benevolente y sacrificado, tanto de los valores existentes en los vínculos y estructuras sociales, como de la participación del bien común correspondiente a los individuos y a los grupos. El amor social es un amor al prójimo que no ha de ser entendido como una mera disposición favorable hacia los demás. Más que predisposición, es acción por el bien ajeno. Implica interés, compromiso y responsabilidad por las personas concretas y por las condiciones en que esas personas viven. Es un concepto que aúna dialécticamente amor y justicia.

La caridad que ama y sirve a la persona no puede jamás ser separada de la justicia: una y otra, cada una a su modo, exigen el efectivo reconocimiento pleno de los derechos de la persona, a la que está ordenada la sociedad con todas sus estructuras e instituciones ${ }^{2}$.

\footnotetext{
${ }^{1}$ Instituto de Derechos Humanos Pedro Arrupe. Universidad de Deusto, Bilbao.

2 JUAN PABLO II (1988) Exhortación apostólica postsinodal Christifideles Laici (ChL), 42.
} 
Expresamente recogido por el magisterio de la Iglesia y su doctrina social ${ }^{3}$, el sentido que alberga ha sido enunciado de diversas maneras: como "amistad" en palabras de León XIII, como "caridad social" en las de Pío XI, que se refiere al amor social como el alma de un orden justo 4 . Pablo VI apostaba por "la civilización del amor que prevalecerá en medio de la inquietud de las implacables luchas sociales y dará al mundo la soñada transfiguración de la Humanidad finalmente cristiana" ${ }^{5}$.

El Concilio Vaticano Il sustenta su crítica a la ética individualista en la idea de que ésta no promueve la dimensión social de la caridad y su compromiso por la justicia.

La profunda y rápida transformación de la vida exige con suma urgencia que no haya nadie que, por despreocupación frente a la realidad o por pura inercia, se conforme con una ética meramente individualista. El deber de justicia y caridad se cumple cada vez más contribuyendo cada uno al bien común según la propia capacidad y la necesidad ajena, promoviendo y ayudando a las instituciones, así públicas como privadas, que sirven para mejorar las condiciones de vida del hombre. ${ }^{6}$

Juan Pablo II ha precisado su riqueza teológica y ha destacado que el amor social es inseparable de la responsabilidad moral por la justicia con los pobres y de la participación política en la vida pública para promover la dignidad y los derechos de las personas. La solidaridad, en cuanto virtuosa preocupación por el bien de todos, ha de ser entendida como una dinámica propia del amor social.

El amor por el hombre y, en primer lugar, por el pobre, en el que la lglesia ve a Cristo, se concreta en la promoción de la justicia. Ésta nunca podrá realizarse plenamente si

\footnotetext{
${ }^{3}$ Benedicto XVI se hace eco y documenta esta trayectoria en su Encíclica Deus caritas est (DCE): "En 1891, se interesó también el magisterio pontificio con la Encíclica Rerum novarum de León XIII. Siguió con la Encíclica de Pío XI Quadragesimo anno, en 1931. En 1961, el beato Papa Juan XXIII publicó la Encíclica Mater et Magistra, mientras que Pablo VI, en la Encíclica Populorum progressio (1967) y en la Carta apostólica Octogesima adveniens (1971), afrontó con insistencia la problemática social que, entre tanto, se había agudizado sobre todo en Latinoamérica. Mi gran predecesor Juan Pablo II nos ha dejado una trilogía de Encíclicas sociales: Laborem exercens (1981), Sollicitudo rei socialis (1987) y Centesimus annus (1991). Así pues, cotejando situaciones y problemas nuevos cada vez, se ha ido desarrollando una doctrina social católica, que en 2004 ha sido presentada de modo orgánico en el Compendio de la doctrina social de la Iglesia, redactado por el Consejo Pontificio lustitia et Pax", que le dedica un capítulo final conclusivo: "hacia una civilización del amor" [CONSEJO PONTIFICIO JUSTICIA y PAZ (2005) Compendio de la Doctrina Social de la Iglesia, nn. 581, 582 y 583], cf. BeNedICTO XVI (2009) Encíclica Deus caritas est, n. 27.
}

${ }^{4}$ Pío XI (1931) Encíclica Quadragesimo Anno (QA), 88 y 137.

${ }^{5}$ Pablo VI (1976) Mensaje para la Jornada Mundial de la Paz 1977: AAS 68 (1976), 709.

${ }^{6}$ Concilio Vaticano II (1965) Constitución Gaudium et spes (GS), 30. 
los hombres no reconocen en el necesitado, que pide ayuda para su vida, no a alguien inoportuno o como si fuera una carga, sino la ocasión de un bien en sí, la posibilidad de una riqueza mayor. Sólo esta conciencia dará la fuerza para afrontar el riesgo y el cambio implícitos en toda iniciativa auténtica para ayudar a otro hombre. En efecto, no se trata solamente de dar lo superfluo, sino de ayudar a pueblos enteros-que están excluidos o marginados- a que entren en el círculo del desarrollo económico y humano. Esto será posible no sólo utilizando lo superfluo que nuestro mundo produce en abundancia, sino cambiando sobre todo los estilos de vida, los modelos de producción y de consumo, las estructuras consolidadas de poder que rigen hoy la sociedad. No se trata tampoco de destruir instrumentos de organización social que han dado buena prueba de sí mismos, sino de orientarlos según una concepción adecuada del bien común con referencia a toda la familia humana.?

Todas estas expresiones que aluden al sentido del "amor social" resaltan el carácter comunitario y público, socio-histórico y político de la caridad, de la fe cristiana y su vida espiritual, y reconocen esa vertiente "social" del amor y de la caridad como una parte nuclear del mensaje de Jesucristo. Es un amor que llama a hacerse cargo de la realidad del mundo y que es "clave de un auténtico desarrollo" (LS 231).

En LS Francisco recuerda las palabras de Benedicto XVI en Caritas in veritate que vienen a sumarse y reforzar el mensaje que nos recuerda el compromiso espiritual de la Iglesia en la lucha por la justicia.

El amor - «caritas»- es una fuerza extraordinaria, que mueve a las personas a comprometerse con valentía y generosidad en el campo de la justicia y de la paz ${ }^{8}$.

Existen diversas formas de manifestación del amor en la esfera de las relaciones interpersonales: la misericordia o la compasión son dos ejemplos de esas otras formas que conviven con el amor social. Lo que distingue a éste de esas otras manifestaciones es su carácter político: su vocación de lucha por la justicia y la transformación de estructuras injustas. Esta dimensión socio-estructural inherente a la praxis del amor social llama a ir más allá para no caer en el asistencialismo o en una beneficiencia paternalista. Es un amor que requiere de una disposición reflexiva, deliberada y comprometida hacia el sentir con el otro. No se fija únicamente en la miseria humana, ni tampoco se recrea en lo común del dolor o la desgracia de las personas. Es un amor que brota del reconocimiento de la grandeza humana y sin el cual no podríamos lamentar la dignidad amenazada de la comunidad-mundo.

\footnotetext{
7 Juan Pablo II (1991) Centesimus Annus (CA), 58.

${ }^{8}$ Benedicto XVI (2009) Caritas in veritate (CiV), 1.
} 
El amor social es un amor amplio y universal, que busca transformar y renovar la sociedad para que sea más fraterna, pacífica y justa con los pobres. Es ágape: un amor fraternal que llama a fortalecer vínculos. Un amor que pide ejercerse en forma de una autentica lucha por una mayor justicia y una mayor libertad en la sociedad. Un amor, en definitiva, de ayuda efectiva que tiene un ápice carismático, de desinterés y olvido de sí mismo. Su ejercicio en la esfera pública se articula dialécticamente con un alcance que transciende lo interpersonal y apela a solidaridades y responsabilidades a escala macrosocial. Es desde esta perspectiva amplia donde la virtud cristiana de la caridad adquiere toda su nobleza. Se trata de un amor que se actualiza en la prosecución del bien común de la sociedad. Un amor encarnado e inspirado, eficaz y cordial: con alma y cuerpo.

Este es el espíritu que alienta la referencia en LS al amor social (LS 231). Allí el papa Francisco señala que cuando "alguien reconoce el llamado de Dios a intervenir junto con los demás en estas dinámicas sociales, debe recordar que eso es parte de su espiritualidad". Son acciones comunitarias que "expresan un amor que se entrega" $y$ "que pueden convertirse en intensas experiencias espirituales." Quien vive la fe a través del amor social puede encontrar en esta experiencia de encuentro con Dios en la misma lucha, no sólo la fuerza para perseverar en la misma lucha, sino el calor de una experiencia afectiva y la plenitud propia de la relación con Dios.

Son experiencias de amor que concretan el sentido de servicio propio de la actitud cristiana, y del dinamismo entero de la vida cristina: anhelan construir una "cultura del cuidado" y nos interpelan a asumir las responsabilidades cristianas en el ámbito público con una "profunda creatividad", "haciéndolo la norma constante y suprema de la acción".

Las referencias del concepto y sentido otorgado por Francisco al amor social expresan de esta manera el ser de la lglesia en clave de servicio de amor/caridad, propiamente llamado diakonía iustituae. Esta acción del amor (y la caridad) social y política, que se compromete por la promoción y el servicio de la justicia, es la entraña de la Iglesia. De esta manera,

la acción a favor de la justicia y la participación en la transformación del mundo se nos presenta claramente como una dimensión constitutiva de la predicación del Evangelio, es decir, la misión de la lglesia para la redención del género humano y la liberación de toda situación opresiva. ${ }^{9}$

\footnotetext{
9 SíNODO DE LOS OBISPOS (1971) La justicia en el mundo. Nuevas responsabilidades de la Iglesia en el campo de la justicia.
} 